\title{
“QuADRILLEROS E SESMEROS QUE MIRAN POR EL BIEN PÚBLICO”: LUCHA Y ASPIRACIONES SOCIOPOLÍTICAS DEL COMÚN VALLISOLETANO A FINES DE LA EDAD MEDIA
}

\author{
BeAtriz Majo Tomé ${ }^{1}$ \\ Universidad de Valladolid
}

\begin{abstract}
Resumen
La constitución del regimiento a mediados del siglo XIV se tradujo en la exclusión del común de la participación política local. No obstante, a lo largo del siglo XV el común de las ciudades castellanas comenzó a reivindicar una mayor participación política lo que se tradujo en un enfrentamiento con las oligarquías que controlaban los regimientos. En este proceso, Valladolid se presenta como un enclave idóneo para analizar las aspiraciones políticas del común, su organización, la articulación de su discurso en torno a la reivindicación de la figura de los procuradores del común, y la lucha para alcanzar dichas aspiraciones, que otorgará al común la experiencia necesaria para poner en práctica un modelo de gobierno revolucionario durante el conflicto comunero.
\end{abstract}

\section{Palabras clave}

Historia urbana; Historia social; Guerra de las Comunidades; conflictos sociales.

\begin{abstract}
The formation of the regimiento in the mid-14th century resulted in the political exclusion of the commons. However, throughout the 15th century, commons from Castilian towns began to demand a grater political participation. This led to the confrontation between the commons and the local oligarchies that controlled the regimientos. In this process, Valladolid is presented as a priviledged place for analyzing some aspects of the commons, such as their political aspirations, their organization, the articulation of a discourse concerning the demand of the figure of the procuradores del común, and the struggle in achieving their aspirations, which gave them the experience they needed to implement a revolutionary local government during the Revolt of the Comuneros.
\end{abstract}

\section{Key words}

Urban History; Social History; Revolt of Comuneros; Social conflicts.

\section{Resumo}

A constituição do "regimiento" em meados do século XIV traduziu-se por uma exclusão da comunidade popular. No entanto, durante o século XV, grupos populares das cidades castelhanas começam a reivindicar uma maior participação política, o que resultou num confronto com as oligarquias que

1 Correo electrónico: beatrizmajo@hotmail.com. 
controlavam os "regimientos". Neste processo, Valladolid apresenta-se como um enclave idóneo para analisar as aspirações políticas da comunidade, a sua organização, a articulação do seu discurso em torno das reivindicações da figura dos "procuradores del cómun", e a luta para alcançar as ditas aspirações, o que lhes permitirá colocar em prática a experiência necessária para implementar um modelo de governo revolucionário durante a "Revolta dos Comuneros".

\section{Palavras chave}

História urbana; História social; Revolta das comunidades; Conflitos sociais.

\section{Introducción}

La implantación de los regimientos en las ciudades y villas castellanas a mediados y finales del siglo XIV, acabó por sentenciar una práctica habitual en los concejos urbanos: la progresiva monopolización de los cargos por parte de un sector social determinado y la aristocratización de la sociedad urbana.

Como consecuencia, el sector no privilegiado de los núcleos urbanos castellanos se vio excluido del gobierno local. En aquellas ciudades en las que se conservó alguna regiduría para el común de la villa, pronto esos cargos acabaron patrimonializados y desvinculados del común para estar en mayor sintonía con la oligarquía ${ }^{2}$. No obstante, el común dio muestras de tener conciencia política, y desde mediados del siglo XV asistimos al despertar político de la comunidad urbana, asociado a la progresiva superación de la crisis de la centuria anterior y a los cambios económicos experimentados en las ciudades de Castilla a fines de la Edad Media ${ }^{3}$. La manifestación más evidente de ese

2 Este aspecto ya fue analizado por Monsalvo Antón quien destacó la escasa presencia de regidurías de pecheros en los regimientos castellanos, a excepción de algunos casos como Sepúlveda, Segovia y Palencia, donde se aprecia una desnaturalización de las regidurías de pecheros a lo largo del siglo XV. José María Monsalvo Antón, "La participación política de los pecheros en los municipios castellanos de la Baja Edad Media. Aspectos organizativos", Studia Historica, Historia Medieval, 7 (1989), pp. 48-55.

3 Sobre el despertar de esta conciencia colectiva del común de las ciudades castellanas: AsEnJo GonZÁlez, "El pueblo urbano: el común", Medievalismo, 13-14 (2004), pp. 181-194; "Acerca de los linajes urbanos y su conflictividad en las ciudades castellanas a fines de la Edad Media", Clío y Crimen, 6 (2009), pp. 52-84; José Ramón Díaz de Durana y Jon Andoni Fernández de Larrea "Acceso al poder y discurso político en las villas cantábricas al final de la Edad Media", Edad Media: Revista de Historia, 14 (2013), pp. 63-80; Asunción Esteban Recio, "La conflictividad social en Palencia desde 1421 hasta la guerra de las Comunidades", Hispania, 75-250 (2015), pp. 467-504; José María Monsalvo Antón, "Ideario sociopolítico y valores estamentales de los pecheros abulenses y salmantino (ss. XIII-XV), Hispania (LXXI/238), 2011, pp. 325-362; Hipólito Rafael Oliva Herrer, “¿Qué tiene de común el “común”? La construcción de la identidad política en Castilla a fines de la Edad Media", Los grupos populares en la ciudad medieval europea, Jesús Ángel Solórzano Telechea y Beatriz Arízaga Bolumburu, (coords.), Instituto de Estudios Riojanos, Logroño, 2014, pp. 241-270; Jesús Ángel Solórzano TelecheA, “The politics of the urban commons in Northern Atlantic Spain in the later Middle Ages", Urban History, 41-2 (2014) pp. 183-203; "por bien y utilidad de los dichos maestres, pescadores y navegantes. Trabajo, solidaridad y acción política en las cofradías de las gentes de la mar en la España atlántica medieval", Medievalismo, 26, 2016, pp. 329-356; Ma Isabel del VAL VALDIVIESO "Oligarquía versus común. (Consecuencias sociopolíticas del triunfo del regimiento en las ciudades castellanas)", Medievalismo, 14 (1994), pp. 41-58; "Ascenso social y lucha por el poder en las ciudades castellanas del siglo XV", En la España Medieval, (17) 1994, pp. 157-184. 
despertar fue la reivindicación de una mayor participación en el gobierno municipal de la comunidad urbana ${ }^{4}$. A fines del siglo XV esa demanda fue general en la Corona de Castilla. El objetivo de la comunidad giraba, ahora, en atenuar "lo que consideraban ser las insuficiencias del gobierno de regidores". La idealización del antiguo concilium, es decir, el concejo más abierto, previo a la instauración del regimiento, y la aparición de nuevos argumentos ideológicos, contribuyeron a fortalecer la reivindicación de la comunidad castellana en las villas y ciudades.

Para analizar este proceso, hemos puesto nuestra atención sobre una villa concreta, Valladolid, cuya importancia en los siglos bajomedievales y, especialmente, en el conflicto comunero, hacen de su estudio un interesante laboratorio en el que analizar este fortalecimiento del común y de sus demandas a lo largo del siglo XV y las décadas previas a la Revolución Comunera. En primer lugar, explicaremos sucintamente el proceso de monopolización del concejo en manos de los caballeros y la instauración del regimiento. En segundo lugar, analizaremos la etapa comprendida entre mediados del siglo XV y la llegada al trono de los Reyes Católicos, un periodo en el que el común adquiere cierta relevancia. Seguidamente, observaremos cómo durante el reinado de Isabel I, el común volverá a ocupar un segundo plano en la sociedad y política local. Los años finales del reinado y la inestabilidad que vivirá Castilla tras la muerte de la reina se produce una agudización de las diferencias entre el común y la oligarquía, finalmente el pacto entre gobernantes y gobernados comienza a resquebrajarse para, asistir a la constitución del común como fuerza política local.

\footnotetext{
4 En los últimos años, investigadores de distintas instituciones académicas europeas han centrado sus estudios en el análisis de la participación política del común, sus aspiraciones, su capacidad organizativa y la elaboración de su discurso político. Entre los principales estudios podemos citar: Cristian LidDy, "Urban conflict in Late Fourteeth-Century England: the case of York in 1380-1", English Historical Review, 118 (2003), pp. 1-32; Andy Wood, "Kett's Rebellion”, Medieval Norwich, Carol Rawcliffe y Richard Wilson (eds.), Londres, 2004, pp. 277-299; Jelle Haemers, For the Common Good. State Power and Urban Revolts in the Reign of Mary of Burgundy, 1477-1482, colección: Studies in European Urban History, 1100-1800, 17, Turnhout, Brepols, 2009; Jelle HaEmers y Christian LidDy, "Popular politics in the late medieval city: York and Bruges", The English Historical Review, 128 (2013), pp. 771-805; Jan Dumolyn y Jelle Haemers, "Patterns of Urban Rebellion in Medieval Flanders", Journal of Medieval History, 31 (2005), pp. 369-393, Marc Boone y Peter Satabel (eds), Shaping urban identity in late medieval Europe, Garant, Leuven, 2000; Wim Blockmans y Antheun Jane (eds.) Showing Stats. Representation of Social Position in the Late Middle Ages, Brepols, Turnhout, 1999; Elodie DesJardin y Anne-Laure Van Bruaene (eds.) De Bono Communi, The discurse and practice of the Common Good in the European City (13th-16th c), Brepols, Turnhout, 2010, 107-146 (colección: Studies in European Urban History, 22).

5 María Asenjo GonzÁlez, "Sociedad y vida política en las ciudades de la Corona de Castilla. Reflexiones sobre un debate", Medievalismo, 5 (1995), p. 116. Para la investigadora, esta reivindicación no respondería ya a una resurrección de los enfrentamientos entre común y caballeros, sino a una postura política que abogaba por "paliar lo que consideraban ser las insuficiencias del gobierno de regidores".
} 


\section{Configuración del gobierno oligárquico y exclusión del común (ss. XIII- XIV)}

La configuración de los gobiernos oligárquicos en las ciudades castellanas fue impulsada por la propia monarquía con el objetivo de consolidar su control sobre las localidades y garantizarse el respaldo de la clase dirigente local en los periodos de crisis política protagonizados por las parcialidades nobiliarias. Alfonso X favoreció el triunfo político de la caballería urbana frente al resto de boni homines de las ciudades y villas castellanas. A partir de ese momento, los caballeros no sólo gozaron de una posición preeminente desde el punto de vista económico (cuyas fuentes de ingreso se habían diversificado gracias a la explotación agrícola y ganadera, además de la tradicional función estamental de la guerra), sino que fortalecieron también su posición política en los concejos locales. Este proceso de oligarquización obtuvo el definitivo espaldarazo a partir de las medidas adoptadas por Alfonso XI que concluyeron con el cierre definitivo de los concejos y su monopolio en manos de la oligarquía local, que se había ido configurando como clase dirigente a lo largo de los dos siglos anteriores ${ }^{6}$. La consecuencia directa fue la confirmación de la exclusión de los pecheros del gobierno local en la mayoría de los regimientos castellanos?

En el caso vallisoletano, la creación del regimiento y su funcionamiento tuvieron como bases el ascenso social de la caballería villana y su organización en dos linajes, Reoyo y Tovar. La reacción de los pecheros, especialmente de su sector más enriquecido, a la exclusión política acabó por determinar la configuración, base social y vías de acceso de los linajes.

Desde mediados del siglo XII, los caballeros villanos y el resto boni homine (principalmente mercaderes y ganaderos), constituía el grupo social predominante. Los diplomas y privilegios otorgados por Alfonso X en 1255 y 1265 a los caballeros vallisoletanos, confirmaron la escisión que venía acentuándose entre ambos grupos. A partir de estos diplomas, los caballeros se garantizaban una realidad jurídica que justificaba su posición social, en un momento en el que su función estamental no era necesaria, y unos privilegios económicos que garantizaban su estatus. Por su parte, la monarquía se garantizaba la fidelidad de una fuerza armada a su servicio ${ }^{8}$.

\footnotetext{
6 Sobre la creación del regimiento: José María Monsalvo Antón, "La sociedad política en los concejos castellanos de la Meseta durante la época del regimiento medieval. La distribución social del poder", Concejos y ciudades en la Edad Media Hispánica. II Congreso de Estudios Medievales, Fundación Sánchez Albornoz, Móstoles, 1990, pp. 359-411.

7 María Isabel del VAL VALDivieso, "Oligarquía versus común. (Consecuencias sociopolíticas del triunfo del regimiento en las ciudades castellanas)”, Medievalismo, 14 (1994), pp. 41-42; José María Monsalvo AnTón, "Transformaciones sociales y relaciones de poder en los concejos de frontera. Siglos XI-XIII. Aldeanos, vecinos y caballeros ante las instituciones municipales", Relaciones de poder, de producción y parentesco en la Edad Media y Moderna, Reyna PASTOR (Coord.), Consejo Superior de Investigaciones Científicas, Madrid, 1990, pp. 109-170; José María Mínguez Fernández, "La transformación social de las ciudades y las Cortes de Castilla y León", Las Cortes de Castilla y León en la Edad Media, Valladolid, 1988, pp. 22-34. 8 El primero de los privilegios, otorgado en agosto de 1255, eximía "del pago de contribuciones ordinarias y extraordinarias a los poseedores de armas y caballos". Diez años más tarde, en 1265, la concesión del Fuero Real fue acompañada de otra serie de privilegios fiscales para aquellos "propietarios de una casa en la
} 
De forma paralela al encumbramiento de los caballeros, las diez familias que los integraban se organizaron en los linajes de Reoyo y Tovar, cada uno de los cuales formado por cinco casas caballerescas. La organización en linajes facilitó el desempeño de los cargos que les otorgaron los diplomas, estableciendo turnos y evitando posibles enfrentamientos.

Una de las consecuencias directas del encumbramiento de los caballeros fue la degradación de los boni homines, asemejados desde entonces al resto de la población debido a su condición de pecheros y excluidos del concejo. No obstante, el desarrollo que experimentó Valladolid en el siglo XIII había beneficiado económicamente a este sector ahora relegado del poder político, lo que impulsó su reivindicación de participar en el concejo.

En circunstancias que desconocemos debido a la falta de documentación, los denominados boni homines, es decir, el sector enriquecido de los no privilegiados, logró una importante victoria en su lucha frente a los caballeros al conseguir la derogación de los privilegios fiscales otorgados en 1255 y 1265 . Pero sus aspiraciones iban mucho más allá, el objetivo final era la participación política del sector enriquecido en el gobierno local, para lo cual se constituyó un partido integrado por esta élite y el resto de la población, los menudos, con una elocuente denominación: La Voz del Pueblo.

$\mathrm{Si}$ apenas conocemos las condiciones en las que se suprimieron los privilegios fiscales, igual de enigmático se presenta el enfrentamiento entre el mencionado partido y los caballeros. Sin embargo, tenemos constancia de que, en enero de 1320, los caballeros habían sido sometidos a la voluntad de la población, como se refleja en un acuerdo por el que se estableció que la mitad de los cargos municipales perteneciesen al partido del pueblo, mientras que la otra mitad sería propiedad de los linajes. Además, se acordaba la restitución de los privilegios fiscales a los caballeros9. Finalmente, este convenio fue ratificado por María de Molina el 22 de marzo de 1321.

Como consecuencia de este acuerdo, los linajes abrieron sus filas para facilitar la integración del sector enriquecido de los pecheros y, de esta manera, canalizar sus descontentos y aspiraciones políticas. Por otro lado, los "menudos" crearon una junta paralela al concejo sin la presencia de representantes del rey en la que administraron bienes comunales y ejercieron presión para lograr su inclusión en el concejo oficial.

aglomeración, de armas y caballos". Además, el diploma determinó el papel preeminente de los caballeros en el seno del concejo local al establecer que los "cavalleros e el merino de el rey en voz de conceio" recibirían el juramento de aquellos oficiales municipales encargados de vigilar y proteger el término. Por último, en 1293, Sancho IV les otorgó otro privilegio que les asimilaba a la nobleza de sangre (a los hijosdalgo) "el derecho a la composición de 500 sueldos y la exención de la justicia ordinaria". Adeline RucQuor, Valladolid en la Edad Media, tomo I, p. 222. Juan Agapito y Revilla, Los privilegios de Valladolid: índices, copias y extractos de privilegios y mercedes reales concedidos a la M.N M. L. y H. ciudad de Valladolid, Máxtor, Valladolid, 2009, ed. facsímil, pp. 57, 54, 80-81.

9 Adeline Rucquor, Valladolid en la Edad Media, Génesis de un poder, Junta de Castilla y León, Valladolid, 1987, tomo I, pp. 349-352. 
No obstante, estas presiones, lejos de desembocar en un nuevo acuerdo, se tradujeron en un conflicto que finalizó con la intervención de Alfonso XI, quien suprimió el partido de La Voz del Pueblo, dejando sin instrumento de organización a los "menudos" 10 . Por su parte, los linajes llevaron a cabo una hábil maniobra al facilitar la integración y fusión del sector enriquecido del común con las familias caballerescas, asegurándose la lealtad y la defensa de los intereses de clase por parte de los nuevos miembros. Por tanto, esta apertura de los linajes puede ser entendida como una mañosa acción encaminada a evitar futuros enfrentamientos y pérdidas de privilegios, y no tanto como un síntoma de debilidad de los linajes.

En cambio, los grandes derrotados fueron los "menudos" quienes quedaron definitivamente relegados del concejo, más aún con la instauración del regimiento a mediados del siglo XIV que consolidó el monopolio del ejercicio del poder político en los linajes, ahora convertidos en bandos-linajes integrados por clientelas.

Los acontecimientos del primer tercio del siglo XIV evidencian que el principal objetivo de la élite del común no era otro que adquirir un estatus político acorde a su estatus económico y no tanto la defensa y representación de los intereses de los no privilegiados. Su liderazgo y participación en la La Voz del Pueblo es utilizado como instrumento para lograr sus fines inmediatos y no como un instrumento de presión y participación que mereciese la pena mantener en el tiempo. Para Adeline Ruquoi, la progresión del antijudaísmo y la política de Enrique de Trastámara canalizarán, a partir de 1360, las frustraciones populares desviando la atención de los gobiernos locales, por lo que el conflicto común- regimiento/oligarquía, quedaría en un segundo plano ${ }^{11}$.

En cuanto a los linajes, hay que resaltar la eficacia de este sistema que evitó la formación de un tercer linaje u organización política que entrase en liza. Sin embargo, la apertura de los linajes no fue una constante, sino que experimentaron etapas de cierre, más frecuentes en el siglo XV, como ha evidenciado Martín Romera en su trabajo sobre la oligarquía vallisoletana ${ }^{12}$. A estas oscilaciones debemos añadir la consolidación de formas internas de discriminación que beneficiaban a las familias antiguas, por ejemplo, reservándose oficios y dificultando la participación e integración de entradizos ${ }^{13}$.

En definitiva, este progresivo cierre de los linajes generó un gran descontento en el sector enriquecido de los no privilegiados que comenzó a utilizar su liderazgo sobre el resto del común para lograr sus objetivos políticos, como ya sucediera a comienzos del siglo XIV.

El fortalecimiento económico del siglo $\mathrm{XV}$, el descontento del resto de no privilegiados ante un regimiento, a su juicio más preocupado por la defensa de los intereses de sus integrantes que de los intereses conjuntos de la villa, y la difusión de postulados

10 Documento transcrito en: Adeline Rucquor, Valladolid en la Edad Media, tomo I, p. 353. El documento se encuentra en: B. N. Madrid, Mss. 11.285, fol. 199-200v.

11 Adeline Rucquor, Valladolid en la Edad Media, tomo I, p. 288.

12 María de los Ángeles Martín Romera, Las redes sociales de la oligarquía de la villa de Valladolid (1450-1520). Universidad Complutense de Madrid, 2012. Tesis doctoral inédita, pp. 545-548.

13 María de los Ángeles Martín Romera, Las redes sociales de la oligarquía..., p. 556. 
humanistas que abogaban por "la responsabilidad moral del ciudadano para con la preservación del bien común", son elementos clave para entender la agudización de las diferencias entre oligarquía y común en las décadas finales de la Edad Media y los acontecimientos ocurridos en los años precomuneros.

\section{Reactivación de la lucha: de las guerras civiles al periodo de regencias}

La ausencia de fuentes impide rastrear la lucha política del común desde su derrota en los años treinta del siglo XIV hasta bien entrado el siglo XV, cuando las Guerras Civiles y la llegada al trono de los Reyes Católicos arrojan, de nuevo, luz sobre cuestiones como la organización, principios e ideario político del común vallisoletano y su capacidad de acción, a pesar de su exclusión del órgano de gobierno local.

El primer indicador de la acción política del común lo encontramos en la participación de la población vallisoletana en defensa del rey Juan II, retenido en Portillo en 1444 por parte de un sector de la nobleza. En Valladolid, gran parte de la oligarquía, que tenía lazos clientelares con miembros de la alta nobleza, pareció no inmiscuirse en el conflicto o, por lo menos, no ofreció una oposición al sector nobiliario contrario al monarca y al Condestable, Álvaro de Luna. Sin embargo, tenemos noticias de que un sector de esta oligarquía y miembros del común sí tomaron partido en favor del monarca y acudieron en su ayuda. Resulta llamativo que esta información se obtenga no por un documento de la época, sino por un documento redactado en tiempos de las Comunidades en el que las cuadrillas vallisoletanas reivindicaron su papel como defensoras del rey y de la Corona frente a los abusos nobiliarios ${ }^{14}$. Esta intervención parece confirmada por una serie de privilegios económicos otorgados por Juan II a Valladolid en los años posteriores a su liberación y que estaban dirigidos a "todos los vecinos y moradores de la villa y de sus arrabales", beneficiando claramente al grupo de pecheros ${ }^{15}$.

Esta división interna entre los sectores vallisoletanos se manifestó de forma más intensa durante las guerras civiles del reinado de Enrique IV cuando el común, organizado en cuadrillas ${ }^{16}$, se posicionó al lado del monarca y se enfrentó a la nobleza alfonsina y a una oligarquía que fluctuó entre ambos bandos.

\footnotetext{
14 Documento analizado en: Hipólito Rafael Oliva Herrer, "La prisión del rey: voces subalternas e indicios de la existencia de una identidad política en las Castilla del siglo XV", Hispania, 71/38 (2011), p. 357 y ss, “QQuién prendió al rey don Juan segundo sino los grandes? ¿Quién le soltó e hiço reinar, sino las comunidades, y especialmente la nuestra, quando en Portillo le tubieron preso?".

15 El primero permitía el intercambio franco de alcabalas en las dos ferias anuales (excepto el pan, el vino, la carne, el pescado salado y algún otro productos alimenticio), mientras que el otorgado en 1453, eximía "de pedidos, monedas, servicios y emprésitos a todos los habitantes de la villa asy xrystianos como judíos e moros que biven e moren e bevieren e moraren dentro del cuerpo e muros de la dicha villa e fuere della en sus arrabales e huertas e alquería, tanto que las alquerías no sean aldeas". Adeline RUcQuoI, Valladolid en la Edad Media, tomo II, pp. 152-153.

16 Demarcaciones que responden a una localización topográfica más o menos comparable con el barrio (parroquias) o las antiguas collaciones. Éstas ejercían funciones militares (como la reparación de la muralla
} 
El episodio más representativo fue el ocurrido el 15 de septiembre de 1464 cuando el Almirante y Juan de Vivero, contador mayor del rey y regidor de Valladolid, se sublevaron en favor del pretendiente al trono. Como respuesta, Alfonso Niño, merino mayor de la villa, se atrincheró en la Puerta del Campo con el objetivo de no rendirla a los nobles rebeldes. Al día siguiente, la comunidad de Valladolid se levantó en apoyo al merino, consiguió sacarlo de la torre, y expulsó a los partidarios de Alfonso. Esa misma noche hacía su entrada en la villa Álvaro de Mendoza, partidario de Enrique.

"E otro día domingo en la tarde se levantó la comunidad contra los dichos y los herederos de la villa, e despojaron todos los más que eran de su opinión de los dichos D. Alonso é Juan de Vivero, é la dicha comunidad sacó al Merino de la dicha torre, y esa noche vino aquí Álvaro de Mendoza con fasta mil rocines de la guarda. Anno Domini mcccclxiiii" ${ }^{17}$.

Al igual que ocurrió tras la liberación del rey don Juan, los privilegios otorgados por Enrique a Valladolid en agradecimiento por su apoyo permiten que asociemos el término "comunidad" empleado en el texto con el sector del común, pues fue el grupo más beneficiado ${ }^{18}$.

A lo largo de los años siguientes la villa fluctuó entre ambos bandos, unas veces mostrándose leal a Enrique y otras cayendo en manos de la nobleza rebelde. En estos años se produjo una constante: cada vez que Valladolid era recuperada por el bando enriqueño, el sector no privilegiado recibía mercedes y privilegios que eran derogados una vez que el sector alfonsino se hacía con el control de la villa ${ }^{19}$. Por lo tanto, es evidente que las cuadrillas vallisoletanas desempeñaron un importante papel en la defensa de la villa en favor del rey legítimo y adquirieron un peso político relevante como demuestra el hecho de que, en 1465, el Almirante de Castilla, partidario del pretendiente al trono, confirmase los antiguos privilegios de Valladolid, especialmente aquellos que reservaban el gobierno municipal a los linajes y prohibían la organización de los vecinos en "voz de pueblo"20.

\footnotetext{
o el reclutamiento para los alardes) y fiscales (redistribución de los impuestos). En Valladolid, las catorce cuadrillas fueron: Arnales, Cal de los Francos, Costanilla, Cuadra, Mercado, Población, Ronco, Reoyo, Ruíz Hernández, San Benito, San Esteban, San Martín, San Pedro y Saúco.

17 Doctor de Toledo, Cronicón de Valladolid (1333-1539), Pedro Sáenz de Baranda, (Ed.), Imp. De la Viuda de Calero, Madrid, 1848, p. 58.

18 Adeline RucquoI, Valladolid en la Edad Media, tomo II, p. 156.

19 Beatriz MaJo Tomé, Valladolid Comunera: Sociedad y conflictos sociales en Valladolid en el tránsito de la Edad Media a la Moderna. Ayuntamiento de Valladolid, Valladolid, 2017, pp. 311-315.

20 Adeline RucquoI, Valladolid en la Edad Media, tomo II, p. 158.
} 
Un elemento clave para comprender la capacidad de acción de las cuadrillas vallisoletanas fueron las Hermandades. Éstas emergieron con fuerza en Castilla en 1464 impulsadas por las ciudades y respaldadas por el propio Enrique IV ya que permitían la organización de las ciudades, importantes aliadas de su causa ${ }^{21}$.

A pesar de la intención del monarca para que una Hermandad general se organizase y consolidase, esto no se había producido. Sin embargo, en 1466 y 1467, tuvo lugar en Valladolid una serie de reuniones de la asamblea general de las Hermandades con el objetivo de reafirmar la fidelidad al rey y organizar su acción. Cabe destacar la fuerte determinación de las cuadrillas vallisoletanas, base de la organización de la Hermandad local:

"Los de Valladolid torcaron en una especie de rabia el pesar de la defección, e infundieron en la Hermandad del pueblo sentimientos de más ardor guerrero, diciendo que ellos podrían poner término por la fuerza a las contiendas, visto que las juntas y conciertos de los Grandes siempre producían funestos resultados" ${ }^{\prime 2}$.

Pero la ruptura de los Pactos de Guisando reavivó el conflicto civil. El 20 de julio de 1468 Valladolid recibió una carta del arzobispo de Toledo, Alfonso Carrillo, y Juan Pacheco, Maestre de Santiago, animándola a abrazar la causa isabelina y prometiéndole importantes privilegios. La contestación de Valladolid fue afirmativa: "todos los cavalleros y regidores desta dicha villa, diputados y los procuradores de las quadrillas della todos juntamente" aceptaron la propuesta. La contestación continuaba con la solicitud de confirmación de franquicias y privilegios " $y$ así mesmo al bien y las honrras de los cavalleros y regidores desta dicha villa que en estos tiempos pasados y casos han sido y son en esta opinión, así en algunas sinrazones si tienen recebidas como en mercedes a los que las tienen, que les sean guardadas"23.

Estas peticiones iban encaminadas a garantizar el monopolio político de los linajes perjudicando a las cuadrillas que, de nuevo, eran relegadas del ejercicio político. Su visto bueno al apoyo del sector isabelino, junto con las peticiones de los caballeros y regidores, puede entenderse, entonces, como resultado de la presión que ejercería este sector sobre la comunidad y sus procuradores, y, quizás, por albergar cierta esperanza de que el discurso isabelino garantizara las libertades urbanas y acabase beneficiando a las cuadrillas.

21 José María SÁnchez Benito, “Observaciones sobre la Hermandad castellana en tiempos de Enrique IV y los Reyes Católicos”, Espacio, Tiempo y Forma, Serie III, Historia Medieval, 15 (2002), pp. 211-212.

22 Adeline Rucquor, Valladolid en la Edad Media, tomo II, p. 162; Alonso de PALEnCIA, Crónica de Enrique $I V$, tomo II, Atlas, Madrid, 1975, p. 42.

23 Adeline RucQuor, Valladolid en la Edad Media, tomo II, p. 166. 
No obstante, la llegada al trono de los Reyes Católicos no se tradujo en premio para quienes habían defendido al rey legítimo y la jurisdicción del realengo. Por un lado, el proyecto político de Isabel y Fernando, orientado a completar el proceso de centralización que venía desarrollándose desde hacía varios siglos, transformó las Hermandades en un instrumento más al servicio de la Corona mediante el control de la Hermandad $\mathrm{General}^{24}$. En segundo lugar, en su afán por estabilizar los reinos tras las guerras civiles, los monarcas consolidaron las formas de gobierno oligárquico confirmando la exclusión del común. En el caso vallisoletano, esta actitud se tradujo en la consolidación de la figura del corregidor y la confirmación del monopolio del regimiento por parte de los linajes, refirmando la exclusión del común. En otras localidades, los Reyes Católicos confirmaron o potenciaron la figura del procurador del común con el objetivo de aliviar las tensiones generadas por esta exclusión ${ }^{25}$, pero no Valladolid, que puede ser explicado por el férreo control ejercido por los linajes en la política local.

No obstante, desde los años noventa del siglo XV se aprecia un reverdecimiento de la lucha del común contra el excesivo control de los linajes y su escasa protección de los intereses generales de la ciudadanía, y la articulación de un discurso en torno a la reivindicación de procuradores del común que controlasen los excesos de los regidores.

\subsection{El conflicto por las ferias de Cuaresma}

En 1491 tuvo lugar un enfrentamiento a tres bandas que involucró al regimiento vallisoletano, al conde de Benavente, vecino de Valladolid, y a los pequeños y medianos artesanos y comerciantes de la villa. Conflicto que se saldó con la progresiva deslegitimación del regimiento, a ojos del común vallisoletano, como órgano de representación y de defensa de los intereses generales de la villa.

Las ferias vallisoletanas habían experimentado una decadencia progresiva a lo largo del siglo XV, agudizada por la irrupción de las ferias de Villalón que, en 1474, obtuvo la franqueza de alcabalas en las ferias de Cuaresma y San Juan, además de un mercado franco semanal. Las ferias de Villalón contaron, también, con el respaldo del conde de Benavente, señor de la villa, que no dudó en utilizar todos sus recursos para consolidar las ferias de su jurisdicción en el circuito ferial castellano ${ }^{26}$.

\footnotetext{
24 Sobre la Hermandad General en el reinado de los Reyes Católicos: José María SÁnchez Benito, "Observaciones sobre la Hermandad...", pp. 209-244 y José María SÁnCHEZ Benıto, "Notas sobre la Junta General de la Hermandad en tiempos de los Reyes Católicos", Anales de la Universidad de Alicante. Historia Medieval, 8 (1990-1991), pp. 147-168.

25 Máximo Diago Hernando, "Transformaciones en las instituciones de gobierno local...”, p. 630; sobre la figura del procurador del común: $\mathrm{M}^{\mathrm{a}}$ Isabel Del VAL VALDIVIESO, "Aspiraciones y actitudes sociopolíticas. Una aproximación a la sociedad urbana de la Castilla bajomedieval", La ciudad medieval. Aspectos de la vida urbana en la Castilla bajomedieval, Juan Antonio Bonachía Hernando (coord.), Universidad de Valladolid, Valladolid, 1996, pp. 213-254.

26 Son numerosas las quejas de los vecinos vallisoletanos que recuerdan cómo el conde entorpeció la llegada de mercaderes a Valladolid entre 1465 y 1480. Adeline RuCQuor, Valladolid en la Edad Media, tomo II, p. 361. A.H.N, Osuna, legajo 526, $\mathrm{n}^{\circ}$ 328, fols. 30-31.
} 
Valiéndose de su influencia sobre el regimiento vallisoletano, donde contaba con la presencia de un hermano y miembros de su propia clientela, consiguió alcanzar un acuerdo por el que el regimiento cancelaba las ferias de Cuaresma de Valladolid del año 1491. En enero de ese año llegó al regimiento una carta de los Reyes Católicos en la que les requería que no hiciesen innovaciones sobre las ferias. La noticia sobre el pacto llegó a oídos de la población que se amotinó el día 24, llegando a irrumpir en la sesión del regimiento, donde exigieron la celebración de las ferias y la redacción de cartas a todas las villas y ciudades informándolas de la convocatoria. Un documento señala que 2.000 personas se levantaron con trompetas y tambores y llegaron a montar maderos en la plaza para construir las tiendas. El texto indica que el levantamiento había sido de tal magnitud "que ha mucho tiempo que nunca en la dicha villa se vio otro tan grande"27.

Las exigencias del común encontraron en Pedro Niño, merino y regidor de Valladolid, un firme defensor. Miembro de una importante familia oligárquica, su padre, Alfonso Niño había defendido la Puerta del Campo en favor de Enrique IV con la colaboración de la comunidad vallisoletana, tras lo cual parece haberse creado un vínculo especial entre la figura del merino mayor y las cuadrillas vallisoletanas como puede observare por el apoyo mutuo que se ofrecieron ante otros ataques o perjuicios de terceros ${ }^{28}$.

Pedro Niño, como merino mayor tenía especial interés en la celebración de ferias puesto que tenía derecho a recibir 1.200 maravedís en cada feria (2.400 anuales) a cambio de no llevar derechos sobre el pan, candelas, madera ni sobre lo que se vendiese en la feria, que pasarían directamente a los bienes de propios del concejo ${ }^{29}$. Además, el merino colocaba una mesa en la plaza del Mercado para llevar a cabo la vigilancia y garantizar el orden y buen funcionamiento de la feria, lo que reforzaba su autoridad y le otorgaba prestigio entre los otros miembros de la oligarquía y, especialmente, entre los regidores ${ }^{30}$.

Pero el conde de Benavente no estaba dispuesto a claudicar y unas semanas después, en febrero, envió a Valladolid a un emisario de nombre Grigalva, con la misión de convencer a los mercaderes vallisoletanos de que acudiesen a la feria de Villalón, lo que aumentó el enfado de la población y originó enfrentamientos como el protagonizado por el emisario y un tundidor, Pedro de Badajoz, que logró amedrentar al emisario, provocando su huida a caballo ${ }^{31}$.

27 A.G.S, RGS, 1491-1, doc. 121.

28 Sirva como ejemplo el respaldo mostrado por las cuadrillas a Pedro Niño cuando en 1476 trató de recuperar el cargo de merino del que había sido desposeído durante un tiempo. Los representantes de las cuadrillas llegaron a personarse en la sesión del regimiento para reclamar la restitución del cargo y de las llaves de la Puerta del Campo a Pedro Niño, hijo de Alfonso Niño, quien con la ayuda de la comunidad había defendido la puerta contra la nobleza rebelde. R.A.H. Colección Salazar y Castro, 9/869, fol. 198-199; A.G.S., RGS, 1476-12, doc. 832.

29 A.M.V, Archivo, 6-20.

30 A.R.Ch.V., Ejecutorias, caja $369, \mathrm{n}^{\circ} 36$. Sobre los conflictos entre la familia Niño y el resto de miembros del regimiento ver: Beatriz Majo Tome, Sociedad y conflictos sociales, pp. 401-419.

31 A.G.S., CCA, Pueblos, leg. 2, doc. 8. 
Las presiones del común parecieron dar sus frutos y desde ese momento, el regimiento inició un pleito con el conde de Benavente ${ }^{32}$. La defensa de las ferias de Cuaresma se convirtió en uno de los ejes centrales de las reivindicaciones de las cuadrillas vallisoletanas que vincularon la celebración de las ferias con los propios intereses de la villa y del bien común.

Por su parte, el regimiento, temeroso de un nuevo levantamiento, inició distintos trámites para garantizar la celebración de las ferias vallisoletanas. Al mencionado pleito de 1491 se sumó en 1503 su oposición a la celebración de una reunión de mercaderes que había comenzado a celebrarse en Medina del Campo y que, según los procuradores de las cuadrillas de Valladolid, no contaba con cédula real y perjudicaba enormemente a Valladolid ${ }^{33}$. Además, son numerosas las noticias que nos ofrecen los libros de actas del regimiento acerca del envío de delegados y comisiones a la Corte para garantizar la celebración de las ferias y agilizar el proceso judicial ${ }^{34}$.

Resulta significativo, como veremos más adelante, que la defensa de las ferias por parte del regimiento se intensifique a partir de 1517, cuando el común ya contaba con procuradores del común, o procuradores mayores como fueron denominados en Valladolid, y el regimiento había sufrido una importante pérdida de reconocimiento como órgano representativo de los intereses locales.

\subsection{Los años cruciales de 1516 y 1517}

La muerte de la reina Isabel en 1504 inició un periodo de inestabilidad política que se prolongó hasta el triunfo realista sobre los comuneros en 1521. En este periodo las ciudades y villas castellanas asistieron con temor a la formación de bandos nobiliarios partidarios de los distintos aspirantes al trono: Fernando el Católico, su yerno Felipe y posteriormente el príncipe Carlos y el infante Fernando.

En este contexto de continuas tensiones, el regimiento de Valladolid adoptó una postura de liderazgo asumiendo la defensa del realengo ante las disputas banderizas y en 1506

\footnotetext{
32 En este pleito se verán involucrados Villalón y su señor, el conde de Benavente, Valladolid y Medina del Campo. Sobre el conflicto de las ferias, ver: María Isabel DEL VAL VALDIVIEso, "Valladolid y las villas de su entorno en el tránsito de la Edad Media a la Edad Moderna", Valladolid, historia de una ciudad. Congreso Internacional. La ciudad y el arte: Valladolid villa (época medieval), VV.AA, Tomo I, Ayuntamiento de Valladolid, Valladolid, 1999, pp. 217-242.

33 Una de las razones esgrimidas era la pérdida de población que sufriría Valladolid si Medina celebrase esas ferias: despoblaría e destruiría (Valladolid) como ya se comiença a azer, porque muchos vecinos desta villa se han ydo e van a vibir a la dicha villa de Medina. A.M.V. Libro de Actas. Años 1502-1514, $1^{\text {a }}$ Parte, fol. 93r. Sesión del 5 de abril.

34 Sirva de ejemplo la comitiva liderada por el corregidor Diego López de Toledo, los regidores Conde de Ribadeo, Álvaro de San Pedro, Francisco de León y Pedro de Tovar, y el mercader Juan Figueroa, que en 1506 se dirigió a la corte para alcanzar el favor real. A.M.V. Libro de Actas. Años 1502-1514, $1^{\text {a }}$ Parte, fols. 207r-209v. Sesiones del 16 y 17 de enero.
} 
entabló conversaciones para la realización de una Hermandad entre las principales localidades de la cuenca del Duero que, finalmente, no tuvo lugar ${ }^{35}$.

Durante estos años no tenemos constancia de conflictos entre el común y la oligarquía, más allá de las frecuentes quejas de la población por la injerencia del concejo en las aldeas o algunos abusos de los regidores en el ejercicio de sus funciones. Debemos esperar al año de 1516 para observar un nuevo capítulo en el conflicto protagonizado por ambos grupos. No obstante, la mención del cargo del "procurador del común" en 1513 pone de manifiesto que el común vallisoletano mantenía viva su aspiración política de obtener representantes directos en el regimiento. Diego Bernal, regidor de la villa, recibió de Juan del Prado, escribano del regimiento, una carta del Cardenal Cisneros en la que se trataba la posibilidad de llevar a la Corte el asunto del procurador. Nada más sabemos acerca de esta negociación, pero parece claro que los regidores, presionados por un común cada vez más fuerte, habrían tenido que plantearse el asunto e incluso iniciar alguna petición a los órganos centrales con el fin de evitar nuevos descontentos ${ }^{36}$.

El año de 1516 supuso un punto de inflexión en el conflicto que venían manteniendo la oligarquía y el común. Los acontecimientos de ese año y del siguiente manifestaron la ruptura total entre las cuadrillas y el regimiento, que quedó debilitado durante los años precomuneros ante el empuje del común.

Ese año, el común de Valladolid se vio perjudicado por dos medidas adoptadas por el regimiento y el cardenal Cisneros y que desencadenaron una oleada de malestar que se tradujo en un levantamiento y la organización armada del común. Ambas medidas fueron adoptadas de forma más o menos paralela generando un caldo de cultivo que propició la insurrección.

Por un lado, el regimiento vallisoletano aprobó una sisa sobre el vino para la construcción de una fuente ${ }^{37}$. Debido a la ausencia de libros de actas para este año y el anterior, no podemos conocer la fecha de su aprobación, pero sí tenemos constancia de que en junio ya se conocía la medida. La sisa generó el malestar de muchos sectores sociales de la villa, incluyendo al sector eclesiástico y universitario que no fueron exentos del pago, razón por la que los provisores de Palencia y el prior y cabildo de Valladolid pusieron en entredicho al regimiento, llevaron la causa a Roma e iniciaron un pleito que llegó al Consejo Real ${ }^{38}$.

El común también manifestó su descontento ante esta nueva carga impositiva. En concreto, en junio, treinta y siete vecinos autoproclamados comunidad, otorgaron carta de representación al merino mayor y regidor Alonso Niño de Castro, al bachiller Francisco Fernández de Alderete y al platero Francisco de Andino para que tramitasen las quejas

\footnotetext{
35 Sobre estas negociaciones y la cancelación de la reunión de las ciudades en 1506 ver: Beatriz MaJo, Valladolid Comunera, pp. 243-251.

36 A.M.V., Chancillería, 45-33; M.A. Martín Romera, Las redes sociales de la oligarquía, p. 658.

37 A.R.Ch.V., Ejecutorias, caja 339, doc. 11 (documento sin foliar).

38 A.G.S., CCA, Pueblos, leg. 21, docs. 160 y 148.
} 
y la oposición a la sisa ${ }^{39}$. Ante la negativa del juez de residencia de aceptar la elección de estos tres hombres como representantes del común, al considerarlo una innovación inválida, el merino ejerció el liderazgo que le habían otorgado y redactó una serie de quejas al Consejo Real en las que informaba de que una posible exención de los clérigos animaría también a los caballeros y a los colegios a solicitarla, aumentándose la carga impositiva sobre los pecheros.

Pero las solicitudes de Alonso Niño no se limitaron al asunto de la sisa. Aprovechando las negociaciones y el creciente clima de hostilidad hacia el regimiento, el merino, que no olvidemos, era a su vez regidor, propuso que el común pudiese juntarse con la justicia para "cosas cumplideras al bien público" y para "otorgar poder para seguir más sus pleitos". Poco después, el 9 de julio, Alonso Niño redactó una nueva carta al Consejo Real exponiendo, de nuevo, el agravio de la sisa y solicitando que el común pudiese tener procuradores que les representasen en el regimiento para contrarrestar el peso de los regidores y evitar el dispendio de dinero público. Consideramos que la carta es suficientemente expresiva para incluirla a continuación:

"Por ser commo es en tanto agrabyo e prejuysio de la dicha communydad especialmente siendo contra los rregidores porque estos por la mayor parte son los que ocupan lo público o toman los vienes de la villa que han pagado los comunes, e sy no se pudiesen juntar con la justicia por licencia de vuestra Alteza como agora lo hizieron, es magnifiesto e notorio agrabyo e contra lo que se tiene en todas las çibdades, villas e lugares de vuestros rreynos donde no solamente non solo se probee de procurador quando semejantes casos se ofresçen, pero de contyno le ay e quadrilleros e sesmeros que miran el bien público, de otra manera la comunidad sería muy agraviada, lo público se ocuparía y lo que peor es que los maravedís que muchas vezes se rreparten que lo pagan los pobres e comunidad, se quedase con los dichos rregidores por no tener los dichos mis partes para prestar poder, no lo aviendo perdido por ninguna causa ni hecho cosa"40.

Esta carta de Alonso Niño de Castro encierra numerosas contradicciones si tenemos en cuenta que él mismo es regidor. Por lo tanto, llama la atención su denuncia del control del dinero público por parte de los regidores y la reclamación de procuradores del común. Este apoyo a las reivindicaciones del común sólo puede entenderse si tenemos en cuenta que el merino mayor de la villa ha mantenido un vínculo estrecho con las

39 El merino había hecho "ayuntamiento particular a boz de pueblo con çiertos oficiales e personas de baxa suerte de la dicha villa, de sus allegados que heran fasta treinta e cinco o quarenta personas" que les habían otorgado el poder de representarles, pero además, habrían hecho "bolsa e rrepartimiento de dinero". A.G.S., CCA, Pueblos, leg. 21, doc. 104. La carta de poder: A.G.S, CCA, Personas, leg. 19. Alonso Niño. 40 A.G.S., CCA, Personas, leg. 19. Alonso Niño de Castro. 
cuadrillas desde mediados del siglo XV, vínculo que a su vez, le permite obtener un importante respaldo social en sus luchas internas con otros regidores y miembros de la oligarquía local. En este sentido, Alonso Niño se presenta como un regidor al servicio del pueblo, alejándose del resto de regidores cuya labor estaba siendo cuestionada en las últimas décadas. Por otro lado, es previsible que Alonso Niño viese con buenos ojos la creación del cargo de procurador del común al considerarlo un posible aliado en las sesiones del regimiento.

Por su parte, el resto de regidores se manifestaron consternados y elevaron sus quejas al Consejo Real aduciendo que estos vecinos habían incurrido en penas por haber elegido "procurador del común e querer pedir que le aya en la dicha villa e aya jurados della" ${ }^{41}$. Sin duda, eran conscientes de que su monopolio político se encontraba no sólo cuestionado, sino que podía llegar a ser menoscabado.

Si la sisa del vino espoleó los ánimos del común, la promulgación y posterior reclutamiento de la Gente de Ordenanza por parte del Cardenal Cisneros acabó por hacer estallar el polvorín en el que se había convertido Valladolid. En enero de 1516 moría Fernando el Católico estableciéndose la regencia del Cardenal hasta la llegada del joven príncipe Carlos. Siguiendo la reforma del ejército iniciada por el rey Fernando, el Cardenal dispuso la creación de milicias urbanas de infantería, y en menor medida de caballería, acantonadas en las distintas localidades castellanas garantizándose una fuerza militar de 30.000 hombres $^{42}$. Pero la medida fue rechazada por numerosas localidades, especialmente de la cuenca del Duero, destacando la oposición firme de Valladolid, cuya postura sirvió de ejemplo para las localidades vecinas ${ }^{43}$.

Por un lado, la medida perjudicaba notablemente a las arcas concejiles puesto que las armas serían sufragadas por las ciudades. En caso de no contar con el dinero suficiente, los regimientos tendrían permiso de echar nuevas sisas y repartimientos. En cuanto a los nobles, veían coartada su capacidad de actuación puesto que las principales localidades castellanas contarían con milicias armadas al servicio de la Corona ${ }^{44}$.

\footnotetext{
${ }^{41}$ A.G.S., CCA, Pueblos, leg. 21, doc. 104.

42 Ante una inminente guerra con Francia, Fernando había iniciado una serie de reformas en el ejército con el objetivo de profesionalizarlo y establecer tropas en Castilla que impidiesen un ataque. Por su parte, el Cardenal, continuó con este propósito alentado también por las tensiones banderizas de los Grandes. La creación de tales milicias no sólo servirían para contrarrestar el ataque francés sino también para disuadir a los nobles de intervenciones contra el regente. René Quatrefages, "La organización militar en los siglos XV-XVI", Actas de las II Jornadas Nacionales de Historia Militar, Diputación de Sevilla, Málaga, 1993, pp. 11-16; María Asenjo GonzÁlez, "Las ciudades castellanas al inicio del reinado de Carlos V", Studia Historica. Historia Moderna, 21, (1999), p. 106; Joseph PÉrez, La Revolución de las Comunidades de Castilla (1520-1521) Siglo XXI, Madrid, 1999, p. 87. José García Oro, El Cardenal Cisneros, vol. 1, Biblioteca de autores cristianos, Madrid, 1992, pp. 356 y ss. Sabina Alvarez Bezos y Agustín Carreras Zalama, Valladolid en época de los Reyes Católicos según el alarde de 1503, pp. 17-18.

43 María Asenjo Gonzélez, "Las ciudades castellanas al inicio del reinado de Carlos V", p. 106.

44 En la carta del secretario Varacaldo del 11 de diciembre puede leerse "Las çibdades son señoras y la justicia muy faborecida, y los grandes, que siempre quieren chupar la sangre al Rey, bebelle la sangre $y$ ponelle en necesidad". Vicente DE LA FUENTE, Cartas de los secretarios del cardenal D. FR Francisco Jiménez de Cisneros, tomo 1, Madrid, 1876, p. 71. El transcriptor nos advierte de que la frase chupar
} 
Sobre el común, es decir, los pecheros, además de recaer la carga impositiva, recaía el propio reclutamiento. Aunque el alistamiento garantizaba ciertas exenciones a los reclutados, esto sólo elevaba la contribución entre quienes debían costearla y, por tanto, el malestar ante la medida.

El 16 de mayo fue aprobada la medida y en los siguientes meses comenzaron a llegar a los distintos regimientos las disposiciones de cómo debía llevarse a cabo el reclutamiento. En Valladolid, el capitán Tapia, encargado de realizar el reclutamiento en la localidad, presentó la disposición el 25 de agosto, siendo debatida en la sesión del regimiento ${ }^{45}$. Los regidores, conscientes de la impopularidad de la medida, trataron de rebatirla alegando que en la villa no había pecheros gracias a un privilegio antiguo ${ }^{46}$. En cuanto al costeamiento de armamento, expusieron su preocupación ante la falta de bienes propios y la imposibilidad de echar sisas debido al malestar reinante ante la sisa del vino que había provocado el entredicho del regimiento por parte de los provisores de Palencia y el cabildo de Valladolid ${ }^{47}$.

Todos los esfuerzos fueron en vano y el 13 de octubre el capitán Tapia se dispuso a llevar a cabo el reclutamiento de 600 vecinos de la villa. El secretario Varacaldo hace referencia al Almirante de Castilla, Fadrique Enríquez y su hermano el obispo de Osma, ambos residentes habituales de Valladolid, quienes alentaron a la población para que se opusiese al reclutamiento, uniéndose otros nobles como el conde de Benavente. Por el contrario, Sangrador Vitores y Antolínez de Burgos, recogen en sus escritos el clamor popular y las iras dirigidas hacia el capitán que se refugió en el convento de San Francisco y huyó de

al Rey, bebelle la sangre aparece subrayada en el texto original con el objetivo de darle énfasis. Manuel Bachiller, beneficiado de Preste resumía: "Animaban a Valladolid algunos de los caballeros, porque decían que no era bien que los pueblos estuviesen armados ni fuertes, porque entonces los caballeros no tendrían fuerzas para defender los agravios que les hiciesen". Manuel BACHILleR, "Antigüedades y sucesos memorables sucedidos en esta muy noble y antigua villa de Simancas", Colección de Doc. Inéditos para la Historia de España, tomo I, Imprenta de la viuda de Calero, Madrid, 1842, p. 530.

45 El capitán Tapia sería el encargado del reclutamiento en Tordesillas, Simancas, Valladolid, merindad de Cerrato y abadengo: "que se nombre entre los vecinos desas dichas villa e merindad e abadengo mill ombres que sean ábiles para la dicha infantería e vecinos e hijos de veçinos desas dichas villas, merindad e abadengo, que sean de los pecheros medianos e menores e de hedad de quarenta annos abaxo e de veyn (sic) arriba a vista e paresçer del dicho Francisco de Tapia, los quales mandamos que gozen de las livertades e esençiones en la dicha ystitaçión e çedulas contenidas" A.G.S., CCA, Pueblos, Valladolid, leg. 21, doc. 96. Otra queja del regimiento ante la posibilidad de que los reclutados portasen armas: A.G.S. CCA, Pueblos, leg. 21, docs. 97 y 158.

46 A.G.S. CCA, Pueblos, leg. 21, doc. 159. Enrique IV confirmó un privilegio dado por Alfonso XI en las Cortes de 1389, en el que hizo a Valladolid y sus aldeas "libres de todo género de pecho, a excepción del yantar y moneda forera, mandando como las aldeas han de pagar 4.200 maravedís en lugar de martiniega y que sean guardados los privilegios y las franquezas e los caballeros armados y el de la franqueza de alarde". J. Agapito y Revilla, Los privilegios de Valladolid: índices, copias y extractos de privilegios y mercedes reales concedidos a la M.N M. L. y H. ciudad de Valladolid, Valladolid, Máxtor, 2009, ed. facsímil, pp. 135-137.

47 A.G.S., CCA, Pueblos, leg. 21, doc. 160. Martínez Romera ha hecho referencia a los problemas económicos a los que tuvo que hacer frente el regimiento vallisoletano debido a la orden de los Reyes Católicos para que Valladolid indemnizase al conde de Benavente por las casas de la Chancillería, que pasaron a ser propiedad de la Corona. María de los Ángeles Martín Romera, Las redes sociales de la oligarquía..., p. 231. 
noche hacia Madrid. Las fuentes destacan la participación acalorada de los vecinos de la Frenería y la Costanilla, dos de las calles más representativas del artesanado vallisoletano ${ }^{48}$. El Cardenal, enterado de los acontecimientos, trató de relajar los ánimos resaltando los beneficios del reclutamiento, pero sus palabras no surtieron efecto por lo que decidió aplastar el motín con las armas. Enterados los vecinos de la villa, se organizaron en una milicia de unos 3.000 hombres, aseguraron las puertas y la muralla, organizaron rondas y vigilaron los caminos ${ }^{49}$.

La desobediencia fue más allá y las cuadrillas, junto con el obispo de Osma y otros miembros del cabildo de la Iglesia Mayor organizaron una asamblea, una junta que llevaba a cabo sus reuniones en la capilla de San Llorente de la Colegiata. El corregidor, incapaz de evitar su constitución, acabó dando licencia a un notario del regimiento, Rosales, y a cuatro regidores para que estuviesen presentes en las sesiones de la junta y sirviesen de enlace entre ésta y el regimiento. Estos cuatro regidores fueron Pedro de Tovar, Gonzalo Franco de Guzmán, Alonso de Saravia y el comendador Santisteban, quienes jugaran un papel importante, en mayor o menor medida, durante la revuelta comunera.

La constitución de esta junta evidencia de forma clara el creciente antagonismo entre las cuadrillas y el regimiento. Ante lo que consideraban una relajación de funciones del gobierno local, que debe velar por el bien común de la villa, las cuadrillas aprovecharon la coyuntura para manifestar su falta de reconocimiento y respaldo a un regimiento que resultaba ajeno a sus intereses. En definitiva, el común, fortalecido por las circunstancias y gracias a los apoyos recibidos por parte de los eclesiásticos, estimó oportuno aglutinarse en un nuevo órgano que defendiese sus intereses. En cuanto a la presencia de regidores en la junta, lejos de considerarlo como una muestra de buena sintonía entre ambos órganos, pensamos que su participación responde a la necesidad del regimiento de mantener una vinculación y diálogo con los amotinados para llegar a acuerdos y evitar mayores disturbios.

La junta se mantuvo durante los primeros meses de 1517 durante los cuales insistieron en la necesidad de la llegada del príncipe Carlos a los reinos peninsulares, la cancelación del reclutamiento y el otorgamiento de una carta de perdón del príncipe a la villa en la que constase que no se tomarían represalias por su amotinamiento. La actitud de Valladolid tuvo un éxito relativo. El reclutamiento finalmente fue modificado de obligatorio a voluntario, por lo que poca gente se alistó. Pero el perdón no llegó tan rápido como se estimaba. Los días 22,23 y 25 de enero fueron leídas en el regimiento varias cartas de los embajadores de Carlos, Laxao (La Chaulx) y el obispo de Tortosa y deán de Lovaina, Adriano de Utrecht, en las que ordenaban la deposición de las armas y la

48 Matías Sangrador VÍtores, Historia de la muy noble y leal ciudad de Valladolid, tomo 1, Grupo Pinciano, Valladolid, 1979 (ed. Facsímil, original, 1851), p. 154; Juan Antolínez de Burgos, Historia de Valladolid, Imprenta y Librería Nacional y Extranjera de Hijos de Rodríguez, Valladolid, 1887, p. 154.

49 Juan Maldonado, La revolución comunera: el movimiento de España, o sea historia de la revolución conocida con el nombre de las Comunidades de Castilla, Quevedo, José (ed.), Imprenta de D. E. Aguado, Madrid, 1840, p. 35. 
cancelación de rondas así como la suspensión de la Gente de Ordenanz ${ }^{50}$. Los miembros del regimiento se dirigieron a la junta donde se debatió acerca de la respuesta que debía darse a los embajadores. La contestación refleja la convicción de la villa, especialmente de los diputados de las cuadrillas, de haber actuado correctamente, en defensa de sus privilegios y ante el miedo a un eventual ataque. Además, esgrimían el amplio apoyo recibido por las distintas órdenes e iglesias (San Benito, Santo Domingo, San Agustín, San Francisco, Trinidad y la Merced) quienes desde sus púlpitos arengaban mediante sermones y proclamas a continuar en su propósito ${ }^{51}$.

Las negociaciones continuaron, pero el perdón de Carlos seguía sin llegar. El corregidor, asegurando que el perdón llegaría, ordenó que se disolviese la junta y revocó los poderes otorgados al notario y a los regidores para poder asistir a las sesiones. Las cuadrillas seguían desconfiando y el miércoles 22 de abril presentaron una carta ante los regidores informando de la necesidad de mantener las rondas y la junta hasta que llegase el ansiado perdón ${ }^{52}$.

Cabe señalar que de forma paralela a estas negociaciones, el regimiento vallisoletano había entablado conversaciones con otras villas y ciudades cercanas con las que pretendía organizarse en Hermandad para solicitar la pronta venida del príncipe Carlos. En este contexto, no es extraño imaginar que las cuadrillas se encontrasen temerosas de una posible intervención contra Valladolid y se mostrasen reacias a deponer las armas ${ }^{53}$.

En cuanto a la junta, resulta llamativa la presencia de miembros del cabildo, así como la ausencia del merino mayor, Alonso Niño, que meses antes había llevado a cabo una férrea defensa de los intereses del común al oponerse a la sisa del vino y a la exención de ciertos sectores sociales. En relación con la institución eclesiástica es necesario recordar el enfrentamiento que mantenían con el regimiento a cuenta de la sisa del vino que se había saldado con el entredicho del regimiento. Además, cabe recordar que el obispo de Osma, uno de los principales instigadores del levantamiento y con un papel activo

\footnotetext{
50 "más que todo lo rrepongáys en aquel punto y estado que estaba antes en el tiempo que la dicha infantería se mandase hazer hasta en tanto quel rrey, nuestro sennor, mande ver en su consejo la dicha ynformaçión (...) y entre tanto, por la presente, en nombre de su Alteza, suspendemos el hazer de la dicha gente” A.M.V., Libro de Actas. Años 1517-1520, $1^{\text {a }}$ Parte, fols. 14-15; 2a Parte, fols. 342-344.

51 "Más asy mismo con autoridad paresçer e consejo e monestaçiones e predicaciones de todos los rreligiosos e predicadores e personas de grant vida e enxenplo e autoridad de todas las hórdenes que ay en esta villa asy de Sant Benito commo de Santo Domingo e Sant Agustín e Sant Francisco e de la Trenidad e de la Merçed, los quales asy en los púlpitos en sus sermones e predicaciones, commo en los ayuntamientos que sobre esto ha fecho e faze esta dicha villa, con mucha ynstançia e amonestaciones, nos han esortado e encargado que prosygamos nuestro propósito como cosa que debemos e somos obligados a hazer e prosegir en servicio de Dios e de su alteza, e en conserbaçión del derecho e libertades e previllejos (...) en esto mismo se an conformado el prior e cabildo e toda la clerecía desta villa y el rrector e doctores e diputados de la Universidad e estudio della e de todas las otras personas de qualquier condición que sean que están en esta dicha villa, asy los naturales della como los estantes pues donde tanta conformidad ay tenemos por cierto que nuestro propósito ha sido y es justo, santo y bueno (...)”. A.M.V., Libro de Actas. Años 1517-1529, $1^{\text {a }}$ Parte, fols. 15v-16.

52 A.M.V., Libro de Actas. Años 1517-1520, $1^{\text {a }}$ Parte, fols. 44-45.

53 Sobre esta Hermandad de 1516-17: Beatriz Majo Tomé, Valladolid Comunera, pp. 251-258.
} 
en la junta, era hermano del Almirante de Castilla, firme opositor al reclutamiento de la Gente de Ordenanza. En cuanto al prior y el cabildo de la Iglesia Mayor poco sabemos de sus motivaciones, más allá del prejuicio de la sisa, sin embargo, la presentación al Cardenal de un escrito del prior y del cabildo solicitando los ansiados procuradores, junto a la firma de todos los cuadrilleros de la villa fue fundamental para la obtención del privilegi ${ }^{54}$. Además, resulta llamativo que durante la Guerra de las Comunidades, la Junta de la Comunidad local estuviese integrada, entre otros, por diputados de dicho Cabildo, como el arcediano de Sanles, manifestando la implicación de sus miembros en la modificación del órgano de gobierno local por otro más representativo en el que participasen diputados de las cuadrillas, de las instituciones eclesiásticas y los regidores ${ }^{55}$.

En segundo lugar, cabe destacar la ausencia de información sobre el respaldo del regidor y merino mayor Alonso Niño de Castro a la junta de 1516. La falta de los libros de Actas del regimiento para ese año dificulta de nuevo la interpretación, sin embargo, podemos deducir que su rechazo o falta de apoyo a la constitución de dicha asamblea estuvo motivada por la oposición del común a la Gente de Ordenanza. Alonso Niño, como merino, tendría gran interés en el reclutamiento ordenado por Cisneros ya que el destacamento vallisoletano quedaría bajo sus órdenes otorgándole un brazo armado, más o menos afín si tenemos en cuenta su vinculación con las cuadrillas o ciertos vecinos, y reforzando su posición ante el resto de regidores ${ }^{56}$.

Por último, es necesario señalar el papel desempeñado por dos miembros importantes de la Chancillería de Valladolid que, indirectamente, contribuyeron al reconocimiento de la asamblea y de las cuadrillas como actores políticos de la villa. Por un lado, ante el cariz que iban tomando los acontecimientos en Valladolid, el Cardenal Cisneros había solicitado al alcalde Leguizamón que le mantuviese informado de las novedades. Así, cuando en noviembre de 1516 el regimiento envió una delegación de regidores para entrevistarse con el Cardenal, a fin de obtener el perdón para la villa, el alcalde le advirtió de que esta delegación acudía sin el visto bueno de la "comunidad" lo que podía genera nuevos alborotos. En su opinión, el licenciado recomendaba al Cardenal que recibiese también a una representación de la comunidad para tranquilizar los ánimos y conocer ambas posturas. El Cardenal accedió a la recomendación y se entrevistó con representantes de la asamblea quienes le solicitaron, además, el privilegio de tener pro-

\footnotetext{
54 Juan Agapito y Revilla, Los privilegios de Valladolid, pp. 222-223 (documento original: A.H.N; Consejos, leg. 29.934, $\mathrm{n}^{\circ}$ 2). El documento de las firmas: A.G.S., PTR, leg. 70, doc. 41.

55 De entre los miembros del Cabildo de la Iglesia Mayor queremos destacar la participación del arcediano de Sanles, que alentó la organización de la junta y que tendrá un papel activo durante la Revolución Comunera (Jerónimo Pérez De Ayala, El Cardenal Cisneros, gobernador del reino: estudio histórico: documentos, Real Academia de la Historia, Madrid, 1928, p. 572).

56 Aunque el encargado de realizar el reclutamiento era el capitán Tapia, parece que la milicia vallisoletana quedaba organizada bajo el mando del merino mayor. Así se desprende de un memorial que recoge ciertas quejas del regimiento sobre los acontecimientos de 1516 en el que puede leerse: "en quanto a tener cargo de la dicha gente porque'l dicho don Alonso es merino y natural y rregidor de alli, sería en grand perjuicio de los vecinos e naturales de la dicha villa e dar ocasión a muchos alborotos y escándalos y rruidos que se podían seguir e pedimos y suplicamos a vuestra alteza mande proveer de otra persona syn sospecha e de fuera para que tenga cargo de la dicha gente” A.G.S, CCA, Pueblos, leg. 21, doc. 104.
} 
curadores del pueblo ${ }^{57}$. Por otro lado, también el Presidente de la Chancillería indujo al Cardenal a la concesión de procuradores del común en una carta fechada el 8 de abril de 1517 que reproducimos parcialmente a continuación:

"Este Arçediano de Sant Soles (Sanles), que allá fue, diz que vino muy favoreçido y contento y ha procurado que el pueblo haga ayuntamientos sin Regidores; hanse de esto escandalizado los Regidores y aunque no llamados, fueronse al Ayuntamiento, onde el pueblo estava. (...). A mi paresçe que aunque esto en algún caso podría convenir, pero que hazer fundamento del pueblo, que es todo vario, inconstante y desasido, sería cosa de poca utilidad y entidad, pero yo por bien avria que el pueblo se diese alguna autoridad en la governaçión, porque templase el mando de los Regidores (...)"58.

En definitiva, las presiones ejercidas por la población durante esos meses y los apoyos recibidos fueron tan enérgicos que finalmente el Cardenal otorgó el privilegio a las cuadrillas para que pudiesen elegir dos procuradores mayores que estuviesen presentes en el regimiento. El día 20 de agosto firmaba Cisneros el privilegio en Aranda de Duero, el 24 fueron elegidos por las cuadrillas y el día 26 recibidos por los regidores, no sin dificultades ${ }^{59}$.

\section{El triunfo del Común: la elección de procuradores mayores}

Las cuadrillas vallisoletanas habían logrado su objetivo y no esperaron en hacer efectivo el privilegio. El 24 de agosto tuvo lugar la elección y presentación de los procuradores mayores en la capilla de San Llorente de la Iglesia Mayor. Allí estaban reunidos representantes del regimiento (el corregidor, Francisco de Luján; el teniente de corregidor, licenciado Luís Godínez de Villaverde y el regidor Alonso Niño de Castro), de la Colegiata (el arcediano de Sanles) y los procuradores menores de las cuadrillas $^{60}$.

La sesión se inició con la presentación del privilegio a las cuadrillas por parte del licenciado Cristóbal de Portillo, que estipulaba qué éstos fuesen designados segund e commo los ha e tiene e elixe la çibdad de Burgos. Una vez leída, el corregidor aceptó

57 María de los Ángeles Martín Romera, Las redes sociales de la oligarquía, pp. 669-672. A.G.S., CCA, Personas, 14-2, Leguízamo (alcalde y licenciado). La delegación del común estuvo formada por Pedro de Torquemada, el arcediano de Sanles, el licenciado Cristóbal de Portillo, Gil de San Pedro, Francisco de Andino y Juan Fanega.

58 Jerónimo PÉREZ DE AYALA, El Cardenal Cisneros, tomo III, p. 572. "Carta de don Diego Ramírez de Villaescusa, obispo de Málaga, presidente de la Chancillería de Valladolid, al Cardenal Cisneros. Valladolid, 8 de abril de 1517 ".

59 A.G.S., RGS, 1517-8, doc. 15; A.H.N., Consejo, leg. 29.934, nº 2. Este documento es una confirmación de Felipe II en el que se inserta el privilegio firmado por el Cardenal.

${ }^{60}$ El proceso de elección: A.M.V., Libro de Actas. Años 1517-1520, $1^{\text {a }}$ Parte, fols. 72-77. 
su cumplimiento y solicitó a los procuradores menores que procediesen a la elección de los dos procuradores mayores. Acto seguido, salió de la capilla permitiendo a los representantes de las cuadrillas votar sin su presencia ${ }^{61}$.

El resultado de la votación fue prácticamente unánime. Los procuradores mayores designados para ocupar el cargo hasta finales de 1518 fueron el licenciado Cristóbal de Portillo y Francisco de Tamayo ${ }^{62}$. Sólo la cuadrilla de la Cuadra no dio su voto a Francisco de Tamayo, sino al mercader Diego de Valladolid. Este hecho nos lleva a pensar que la elección de ambos ya se habría acordado de antemano, lo que no debe de extrañarnos si tenemos en cuenta que la reivindicación de procuradores mayores había sido uno de los ejes centrales de los acontecimientos de 1516 y 1517.

Al día siguiente, 25 de agosto, don Pedro de Torquemada, arcediano de Sanles, junto al escribano del regimiento, Juan de Prado, dio fe en el regimiento de la elección de procuradores mayores por parte de las cuadrillas ${ }^{63}$. Las posturas de los regidores se dividieron entre quienes se oponían frontalmente a la elección de procuradores mayores y quienes la aceptaron siempre y cuando jurasen fidelidad a la Hermandad establecida entre Valladolid, León y Burgos, y las cuadrillas pusiesen fin a las rondas que continuaban haciéndose en la villa ${ }^{64}$.

Finalmente, a pesar de la oposición de la mayor parte de los regidores, los procuradores mayores fueron recibidos y aceptados en el regimiento el día 26, jurando éstos lealtad a la Hermandad ${ }^{65}$.

${ }_{61}$ Los procuradores menores habían sido designados por sus respectivas cuadrillas los días 23 y 24 como consta en la carta de poder que dieron los cuadrilleros de la Cuadra y San Esteban a sus procuradores (A.M.V., Libro de Actas. Años 1517-1521, $1^{\text {a }}$ Parte, fols. 78-80). Los regidores de la cuadrilla del Mercado fueron el bachiller Alderete y Antonio de Olande; de Ruiz Hernández: Francisco de Torquemada y Pedro de Mayorga; de Cal de Francos: el bachiller Andrés Gutiérrez y Alonso Gutiérrez de Villalón; de Arnales: Hernando López de Calatayud y Alonso de Vera; del Ronco: el licenciado de Baeza y Alonso Álvarez de Solares; de la Costanilla: Francisco de Andino y Juan Fanega, plateros; de Reoyo: García de Dueñas y Alonso de Velliza; de Población: Juan de Saldaña, confitero, y Juan de Barrantes; de la Cuadra: el bachiller de León y el bachiller Colina; de San Benito el Viejo: Cristóbal Gallego y Pedro Gigante; de San Martín: Juan de San Pedro y Gil de San Pedro; de San Pedro: Gómez de Revilla y Juan Calderón; de San Esteban: el bachiller de Medina y Sebastián de Pesquera; del Saúco: Alvar Rodríguez de Cigales y Juan Rodríguez de Valladolid. A.M.V., Libro de Actas. Años 1517-1520, $1^{\text {a }}$ Parte, fols. 72v-73r.

62 El cargo de procurador mayor tenía una periodicidad anual, siendo elegidos a principios de enero de cada año, sin embargo, este primer año se resolvió que los procuradores ejerciesen su cargo de agosto a diciembre de 1517 y enero a diciembre de 1518

63 A.M.V., Libro de Actas. Años 1517-1520, $1^{\text {a }}$ Parte, fol. 82; 2a Parte, fols. 404-405.

64 Eran de este parecer el comendador Cristóbal de Santisteban, Gonzalo Franco de Guzmán -que habían sido representantes del regimiento en la junta paralela de 1516/17- y Bernaldino Pimentel. Recordamos que la Hermandad y confederación pactada con ambas localidades estaba destinada a solicitar al príncipe Carlos su venida a Castilla, evitar que los cargos y beneficios fuesen otorgados a extranjeros y la salida de dinero de Castilla.

${ }_{65}$ Los regidores que mostraron un rechazo más enérgico a los procuradores mayores fueron: García de Alcocer, Diego Vernal, Pedro de Tovar, Juan Rodríguez de Baeza y Rodrigo de Verdesoto (A.M.V., Libro de Actas. Años 1517-1520, $1^{\text {a }}$ Parte, fols. 82-84). 
Las personas que ejercieron el cargo de procuradores mayores en los años precomuneros fueron:

\begin{tabular}{|c|c|c|}
\hline Año 1517-1518 & Años 1519 & Año 1520 \\
\hline $\begin{array}{l}\text { Francisco de Tamayo } \\
\text { - Mercader } \\
\text { - Rechazado por una casa en } \\
\text { enero de } 1517 \\
\text { - Contino }\end{array}$ & $\begin{array}{l}\text { Francisco de Torquemada } \\
\text { - Mercader } \\
\text { - Miembro de linaje } \\
\text { - Fracasó en su intento de } \\
\text { obtener una procuraduría } \\
\text { de Cortes }\end{array}$ & $\begin{array}{l}\text { Francisco de Saldaña } \\
\text { - Platero } \\
\text { - Miembro de linaje }\end{array}$ \\
\hline $\begin{array}{l}\text { Licenciado Cristóbal de } \\
\text { Portillo } \\
\text { - Licenciado del regimiento } \\
\text { - Yerno del mayordomo de } \\
\text { los propios } \\
\text { - Miembro de linaje }\end{array}$ & $\begin{array}{l}\text { Francisco de Saldaña } \\
\text { - Platero } \\
\text { - Miembro de linaje }\end{array}$ & $\begin{array}{l}\text { Pedro Hernández de } \\
\text { Portillo } \\
\text { - Mercader } \\
\text { - Emparentará con la familia } \\
\text { Acuña }\end{array}$ \\
\hline
\end{tabular}

Como puede apreciarse, quienes desempeñaron el cargo en los años previos a la Revolución Comunera, fueron personas distinguidas dentro de las cuadrillas, estando vinculadas tanto a éstas como a los linajes oligárquicos y, por lo tanto, formando parte de sus clientelas ${ }^{66}$.

A pesar de no tener voz ni voto en el regimiento, la presencia de estos cargos provocaba gran incomodidad entre los regidores que vieron limitada su capacidad de acción. Además, el debilitamiento del regimiento ante la sociedad vallisoletana generó que los procuradores del común sí tuviesen un papel activo y fuesen oídas sus opiniones y consideraciones en las sesiones del regimiento. Entre sus preocupaciones destacaron ciertas sisas y gastos, la venta de ciertos productos alimentarios como el pescado, carnes y sus precios y, por supuesto, la defensa de las ferias vallisoletanas ${ }^{67}$.

Queremos destacar el papel desempeñado por Francisco de Saldaña, procurador mayor en 1518, que ejerció su cargo con fervor y dirigió sus esfuerzos hacia la construcción de un palacio que el conde de Benavente estaba construyendo en Valladolid, próximo

66 Sobre el perfil de los procuradores mayores y menores de estos años previos a la Revolución, Beatriz Majo Tomé, Valladolid Comunera, pp. 185-192; 340-347; 630.

67 Sobre las carnicerías: A.M.V., Libro de Actas. Años 1517-1520, $1^{\text {a }}$ Parte, fol. 93v; A.M.V., Libro de Actas. Años 1517-1520, 2a Parte, fols. 549v y 591r; sobre sisas: A.M.V., Libro de Actas. Años 1517-1520, $2^{\mathrm{a}}$ Parte, fol. 478r; sobre gastos: A.M.V, Libro de Actas. Años 1517-1520, $1^{\mathrm{a}}$ Parte, fol. 104v y $2^{\mathrm{a}}$ Parte, fol. 551r; sobre las ferias: A.M.V, Libro de Actas. Años 1517-1520, $2^{\text {a }}$ Parte, fol. 771v y A.G.S., CCA, leg. 132 , doc. 30 , fol. $18 \mathrm{v}$. 
al Puente Mayor. Aprovechando la ausencia de regidores, que se habían desplazado a pueblos del alfoz debido a un brote de peste que afectó a la villa en 1518, Francisco de Saldaña paralizó la construcción del palacio alegando que se trataba de una fortaleza que podía ser utilizada por el conde para albergar sus tropas y hacerse con el control de la villa ${ }^{68}$. No obstante, una vez regresaron los regidores, no encontraron motivos para detener la construcción ${ }^{69}$.

En definitiva, las cuadrillas vallisoletanas habían logrado su ansiado objetivo de tener una mayor participación política y una mejor representación en el regimiento. Además, el conflicto mantenido con la oligarquía había debilitado notablemente al concejo de tal manera que los procuradores mayores tuvieron mayor capacidad de acción de la que, a priori, les confería el privilegio.

La lucha, además, había potenciado la organización del común en torno a las cuadrillas, había contribuido a la construcción de un discurso reivindicativo y justificativo de sus aspiraciones y les había conferido un reconocimiento como sujeto político lo que condicionó la evolución de la Revolución Comunera, no sólo en Valladolid sino en el contexto general del movimiento.

\section{Epílogo: la revolución comunera}

Tres años después de la concesión del privilegio a las cuadrillas tuvo lugar la incorporación de Valladolid al movimiento comunero. El 22 de agosto de 1520 llegó la noticia de que la vecina Medina del Campo había sido atacada por los realistas, en su intento de tomar la artillería almacenada en el cuartel con el fin de emplearla para acabar con la insurrección en Segovia. Este acontecimiento fue decisivo para que muchas localidades, como Valladolid, que hasta entonces había mostrado una actitud dubitativa, abrazasen la causa comunera ${ }^{70}$.

El 24 de agosto se celebró la primera sesión de la Junta de la Comunidad de Valladolid que asumió las funciones de órgano de gobierno local en sustitución del desmantelado

\footnotetext{
68 Cabe recordar que el conde de Benavente tenía a una fortaleza en Cigales y otra en Portillo, ambas próximas a Valladolid.

69 Sobre este conflicto, Beatriz Majo Tomé, Valladolid Comunera, pp. 215-225; Felipe Ruíz Martín, "Disensiones en Valladolid en vísperas de las Comunidades de Castilla. El palacio del conde de Benavente: ¿Fortaleza o mansión?”, Cuadernos de Investigación Histórica, 2 (1978), pp. 443-458; A.G.S., CCA, Memoriales, leg. 132, doc. 30.

70 Sobre la quema de Medina del Campo, Prudencio de SAndoval, Historia de la vida y hechos del Emperador Carlos V, máximo, fortísimo, Rey Católico de España y de las Indias, Islas y Tierras firmes del mar Océano, Madrid, 1955, Carlos Seco Serrano, edición y estudio preliminar, tomo I, pp. 248-251; Fernández Martín, L., «El incendio de Medina del Campo: 21 de agosto de 1520. Un testimonio inédito», Investigaciones históricas: Época Moderna y contemporánea, 13 (1993), pp. 95-106; Joseph PéREz, La revolución de las Comunidades, pp. 177-178.
} 
regimiento ${ }^{71}$. En esa sesión se acordó que, además de los procuradores de las cuadrillas, en adelante asistiesen a las sesiones dos diputados del estado de la Iglesia -los que el cabildo proveyese- y dos del estado de los caballeros, don Pedro de Bazán y don Bernaldino Pimentel ${ }^{72}$. Un mes después, el 6 de octubre, a petición de los regidores Gonzalo Franco de Guzmán y Juan Rodríguez de Baeza, se aprobó que, en adelante, pudiesen entrar los caballeros y los vecinos de la villa en las sesiones para procurar el bien común ${ }^{73}$.

En definitiva, la gobernanza de la villa era asumida ahora por un nuevo órgano, con una base mucho más representativa y participativa que el anquilosado regimiento, permitiendo no sólo la participación de regidores y otros nobles sino también del cabildo de la Colegiata, lo que puede ser entendido como un reconocimiento a la ayuda que prestaron a las cuadrillas para la obtención del privilegio de los procuradores mayores. Esta nueva junta recuerda notablemente a la asamblea constituida en 1516 en la que representantes de las cuadrillas, del cabildo e incluso algunos regidores, organizaron su oposición a la Gente de Ordenanza y plantearon sus reivindicaciones políticas. Destaca, además, que las reuniones no se celebrasen en las casas del concejo sino en la capilla mayor de la Colegiata, o Iglesia Mayor, cerca de la capilla de San Llorente donde años atrás se había constituido la asamblea. La Colegiata se había constituido en un símbolo de la oposición al regimiento tradicional además de convertirse en un sólido apoyo gracias al respaldo del prior y el cabildo.

En este contexto, la figura del procurador mayor carecía de sentido. Las cuadrillas tenían ahora mucha mayor representación al contar con dos diputados cada una (los anteriormente denominados procuradores menores). No obstante, Pedro Hernández del Portillo y Francisco de Saldaña desempeñaban el cargo durante 1520. Del primero no tenemos noticias, mientras que Pedro Hernández del Portillo se habían negado a asumir el liderazgo de la insurrección el 22 de agosto, sufriendo las iras de la población, descontenta por la falta de implicación de sus representantes ${ }^{74}$. Este hecho y la apertura participativa del nuevo órgano de gobierno podría haber supuesto la supresión

\footnotetext{
${ }^{71}$ Al contrario que en Burgos, León, Soria y Palencia, donde el regimiento se mantuvo aunque ampliando sus bases participativas, en el caso vallisoletano fue eliminado y sustituido por una junta comunera. Sobre la constitución de gobiernos revolucionarios en la revolución comunera: Máximo Diago Hernando, "Transformaciones en las instituciones de gobierno local de las ciudades castellanas durante la Revuelta Comunera (1520-1521)", Hispania, 63/2, 214 (2003), pp. 640-646.

72 A.G.S., PTR, leg. 4, doc. 54, fol. 568r.

73 A.G.S., PTR, leg. 4, doc. 54, fol. 570v: "para que recibiesen parte del trabajo en la provisión del bien común della". Ese día se acepta que estén presentes en la Junta el doctor Espinosa, el doctor Pero López y el licenciado Burgos, que tendrán una presencia activa redactando cartas y tomando informaciones a los delincuentes (A.G.S., PTR, leg. 4, doc. 54, fol. 571).

74 Pedro Hernández del Portillo no sólo se negó a ejercer el liderazgo sino que, además, desacreditó la sublevación calificándoles de "alborotadores y ladrones, que andaban a robar". Ante estos descalificativos, la muchedumbre dirigió sus iras contra el procurador: "salid acá traydor, que avéis vendido la villa", Prudencio de Sandoval, Historia de la vida y hechos, tomo I, p. 253; Juan Ortega Rubio, "Las comunidades de Castilla en Valladolid", Investigaciones acerca de la Historia de Valladolid, H. de Rodríguez, Valladolid, 1887, p. 129.
} 
del oficio, sin embargo, los vecinos no estaban dispuestos a perder un cargo que había sido la piedra angular de sus reivindicaciones en los años anteriores y solicitaron al Cardenal Adriano que se les permitiese elegir nuevos procuradores mayores ${ }^{75}$, cargos finalmente asumidos por Velasco de Cueto y Pedro de Mayorga ${ }^{76}$ que, no obstante, apenas son mencionados en la documentación, lo que demuestra que el cargo quedó vacío de contenido, pero mantuvo su simbolismo.

Si la reivindicación de participación política directa del común había sido una constante en su discurso durante las décadas precomuneras, también lo había sido su oposición frontal al conde de Benavente. En este sentido cabe destacar que, a pesar de que el conde trató de evitar la incorporación de Valladolid al movimiento comunero mediante la vía diplomática y el bueno tono en sus requerimientos, los comuneros vallisoletanos rechazaron cualquier entendimiento. Cuando en noviembre de 1520 el sector más radical de los comuneros se hizo con el control de la villa y sus instituciones, las cuadrillas intensificaron su carácter antiseñorial, manifestado claramente en la respuesta que ofrecieron al Almirante en enero de 1521 ante sus insistencia para que depusieran las armas y se rindiesen, y en la solicitud que hicieron al capitán comunero Juan de Padilla para que destruyese la fortaleza que el conde tenía en Cigales ${ }^{77}$.

En definitiva, la Revolución Comunera permitió al común vallisoletano poner en práctica una concepción de participación política que venían defendiendo desde tiempo atrás en la cual las cuadrillas adquirían un papel protagonista.

\section{Conclusiones}

La lucha del común por obtener una participación política más representativa y directa se presenta como el motor dinamizador de la conflictividad vallisoletana en los años precomuneros. Esa lucha no sólo afectó a los dos grupos enfrentados, oligarquía y común, sino que, en un momento determinado, acabó por hacer partícipes a todos los sectores sociales e instituciones de Valladolid, como manifiesta el apoyo de la Iglesia y la Universidad a las cuadrillas.

Por otro lado, los momentos de crisis políticas fueron el contexto idóneo para que las cuadrillas vallisoletanas asumiesen responsabilidades en la organización y gobernanza de la villa. Así había sucedido durante la guerra civil que enfrentó a Enrique IV con

\footnotetext{
75 A.G.S., RGS, 1520-09.

76 A.G.S., PTR, leg. 4, doc. 53, fol. 434v.

77 Carta del Almirante: Manuel Dánvila, Historia crítica y documentada de las Comunidades de Castilla, en Memorial histórico español: colección de documentos, opúsculos y antigüedades que publica la Real Academia de la Historia, Est. Tip. De la viuda e Hijos de M. Tello, Madrid, 1898, tomo III, pp. 89-91; Prudencio de Sandoval, Historia de la vida y hechos del Emperador Carlos V, tomo I, Madrid, pp. 288389. La contestación de Valladolid: Manuel Dánvila, Historia crítica y documentada, tomo III, pp. 91-94; A.G.S., PTR., Comunidades de Castilla. Leg. 4, doc. 49, fols. 218-219r; Biblioteca Nacional de Madrid, Ms. 1779. La petición a Padilla: A.G.S., PTR, leg. 4, doc. 54, fol. 579v.
} 
un sector de la nobleza, y así sucedió de nuevo en 1516-1517, cuando, respaldadas por otros sectores, constituyeron una asamblea en defensa de sus intereses.

El discurso del común se articuló, por tanto, en torno a la defensa de los intereses de Valladolid, vinculando esos intereses con los del propio grupo del común, y desvinculándolos con los de la oligarquía. Ésta, integrada en los linajes de Reoyo y Tovar hacía tiempo que utilizaba su monopolio en el regimiento para garantizar sus intereses y los de los miembros de la nobleza con quienes tenían vínculos clientelares. Entre ellos, destaca el conde de Benavente, que se erigió como el gran enemigo externo del común vallisoletano. De hecho, junto con las acusaciones al regimiento, otro de los elementos principales del discurso del común fue su oposición a las presiones ejercidas por el conde. El desprestigio progresivo del regimiento, cuestionado por las cuadrillas vallisoletanas, y los acontecimientos acaecidos en 1516 acabaron por favorecer a las aspiraciones políticas de las cuadrillas que, finalmente, obtuvieron sus ansiados procuradores mayores. Tres años más tarde, en 1520, gracias a la coyuntura de la revolución comunera, las cuadrillas dieron un paso más allá en su lucha por un gobierno local más representativo y participativo con la supresión del regimiento y la instauración de una junta comunera. En definitiva, la experiencia adquirida en los años previos condicionó notablemente el desarrollo de la revolución en la villa dotándole de un marco organizativo, un discurso y unas aspiraciones que venían perfilándose desde hacía décadas.

Fecha de recepción: 11 de noviembre de 2016

Fecha de aceptación: 31 de marzo de 2017 